\title{
Erratum to: Picosecond lasers for tattoo removal: a systematic review
}

Ofer Reiter ${ }^{1} \cdot$ Lihi Atzmony $^{1} \cdot$ Lehavit Akerman $^{1} \cdot$ Assi Levi $^{1} \cdot$ Ruben Kershenovich $^{1}$. Moshe Lapidoth $^{1,2}$ - Daniel Mimouni ${ }^{1,2}$

Published online: 14 December 2016

(C) Springer-Verlag London 2016

Erratum to: Lasers Med Sci (2016) 31:1397-1405

DOI 10.1007/s10103-016-2001-0

The published online version contains a mistake in the article note. The article contains an additional sentence on the author's contribution which is incomplete. The corrected article note is shown below.

Moshe Lapidoth and Daniel Mimouni contributed to the work equally.

The online version of the original article can be found at http://dx.doi. org/10.1007/s10103-016-2001-0.

\footnotetext{
Ofer Reiter

Ofer83@gmail.com

1 Department of Dermatology, Rabin Medical Center, Beilinson Campus, 39 Jabotinski St., Petach Tikva, Israel 49100

2 Sackler Faculty of Medicine, Tel Aviv University, Tel Aviv 6997801, Israel
} 